\title{
O ENSINO DE ATUALIDADES E OS DESAFIOS DE COMPREENDER O TEMPO PRESENTE: Uma Perspectiva Transdisciplinar
}

\author{
Márcia Juliana Santos ${ }^{1}$ \\ Alberto Luiz Schneider ${ }^{2}$
}

\begin{abstract}
RESUMO
Interessa a este artigo refletir sobre o ensino de atualidades e do tempo presente numa perspectiva interdisciplinar e transdisciplinar, tendo como referência a análise de algumas práticas docentes de professores da rede privada de São Paulo. Pensar as implicações do ensino do presente, necessariamente remete às preocupações de educadores que buscam enfrentar a polarização ideológica e a conjuntura de pós-verdade, que marcam os desafios da contemporaneidade. 0 artigo tece críticas às noções de neutralidade, imparcialidade e verdade absoluta. Por fim, convida o professor para adotar um projeto educacional voltado para uma atitude contemporânea diante da provisoriedade das análises acerca do tempo presente.
\end{abstract}

Palavras-chave: Ensino de atualidades. Tempo presente. Transdisciplinaridade. Pluralidade.

\section{CURRENT TEACHING AND CHALLENGES TO UNDERSTAND THE PRESENT TIME:}

\section{A TRANSDISCIPLINARY PERSPECTIVE}

\section{ABSTRACT}

It is interesting to reflect on the teaching of current and present time in an interdisciplinary and transdisciplinary perspective, having as reference the analysis of some teaching practices of teachers of the private school of São Paulo. Thinking about the implications of teaching the present necessarily refers to the concerns of educators who seek to confront ideological polarization and the post-truth situation that mark the challenges of contemporary times. The article criticizes the notions of neutrality, impartiality and absolute truth. Finally, he invites the teacher to adopt an educational project aimed at a contemporary attitude towards the provisional analysis of the present time.

Keywords: Teaching of news. Present time. Transdisciplinarity. Plurality.

RECEBIDO EM: 9/4/2018

ACEITO EM: 29/5/2018

\footnotetext{
${ }^{1}$ Professora de História e Atualidades no Ensino Médio, na rede particular de São Paulo. Doutora em História (PUC-SP), com Pós-Doutorado no Departamento de História da USP. É autora de livros didáticos na área de História. Publicou o livro It's All True: o Brasil de Orson Welles, 19421993 (Alameda, 2015), além de vários artigos em revistas acadêmicas, nas áreas de História e cinema e atualidades. majusan1@hotmail.com

2 Professor de História do Brasil no Departamento de História da PUC-SP e do Mestrado Profissional em Práticas Docentes no Ensino Fundamental da Universidade Metropolitana de Santos (Unimes). Doutor em História pela Unicamp (2005), com Pós-Doutorado no King's College London (2008) e no Departamento de História da USP (2011). Foi professor convidado na Tokyo University of Foreign Studies (2004-2007). Publicou o livro Silvio Romero: hermeneuta do Brasil (Annablume, 2005), além de vários artigos no Brasil e no exterior. alberto.Is@uol.com.br
} 
Este artigo foi inspirado na experiência docente de seus autores e no acompanhamento de atividades desenvolvidas por alguns professores da rede particular da cidade de São Paulo e da Grande São Paulo, cujo trabalho tem sido o de compreender o tempo presente por meio de disciplinas da área de Ciências Humanas, Linguagens e Atualidades. As atividades de observação, análise e registro do trabalho desses professores vêm sendo feitas há pelo menos 5 anos. Para a escrita deste artigo as reflexões apresentadas têm como inspiração o trabalho desenvolvido por professores de uma escola situada na Grande São Paulo e outras duas escolas localizadas na zona sul da capital paulista. O que há em comum entre essas escolas? Seu público-alvo é de classe média, os professores apresentam boa formação acadêmica e cultural e os alunos obtêm excelentes resultados em avaliações externas.

Além dessas três escolas, percebe-se que outras instituições privadas de Ensino Médio em São Paulo têm oferecido em sua grade curricular uma nova disciplina chamada "Atualidades", ministrada por um(a) professor(a), em geral graduado(a) em História, Geografia, Filosofia ou Ciências Sociais. Também as escolas públicas ${ }^{3}$ têm ensinado conteúdos de atualidades por meio dessas disciplinas.

Essa nova disciplina ou campo interdisciplinar, todavia, não tem recebido a devida análise por parte dos profissionais ou teóricos da educação. Antes de adentrarmos, contudo, nas especificidades do ensino de atualidades, uma questão se impõe desde já: qual é o significado do termo "atualidade" em educação? Qual a relação deste termo com outros conceitos como "tempo presente" e "contemporaneidade"? E, por fim, como e por que se deve ensinar atualidades no hoje?

\section{DEFININDO CONCEITOS}

No início do século 20, "atualidades" era o nome de curtas-metragens que noticiavam fatos do presente, novidades da vida pública ou vivências cotidianas que despertavam a curiosidade do espectador frequentador das salas de cinema.

Para além do cinema, até hoje, a expressão remete à ideia daquilo que é contemporâneo, que ocorre "aqui e agora". Diz respeito a fatos e a processos situados no presente. Representa ainda discursos sobre a contemporaneidade, marcada por um tempo polifônico e polissêmico. Polifônico, pois as vivências em sociedades são signatárias de visões de mundo diversas. Crescer na favela da Maré, no Rio de Janeiro, estudar na escola pública do bairro e representar minorias marginalizadas, como foi a realidade da vereadora Marielle Franco, assassinada no início de março de 2018, não é o mesmo que crescer em um condomínio fechado de classe média e estudar em escola privada de um bairro rico de qualquer cidade brasileira. Essas sociedades também são polissêmicas, pois produzem muitas sensibilidades assinaladas por diferentes sentidos conferidos à existência humana.

\footnotetext{
3 Caberia uma análise acerca das experiências na rede pública estadual, todavia os contextos são bem diferentes e os desafios enfrentados pelo cotidiano escolar dessas escolas exigiria a mobilização de saberes mais específicos. 
O processo de destituição da presidente Dilma Rousseff, por exemplo, pode ser enunciado como impeachment, o que indica legalidade e legitimidade ao processo, ou pode ser denunciado como "golpe parlamentar", sugerindo a manipulação do ordenamento jurídico para elevar ao poder um governo sem o consentimento do voto, portanto ilegítimo. Qualquer professor que tenha enfrentado, em sala de aula, a natureza social e política desses dois temas anteriormente citados, inevitavelmente precisou encarar a polifonia e a polissemia que atravessam a contemporaneidade brasileira.

Alguém poderia perguntar: Quando começa essa contemporaneidade? Não há respostas inequívocas para essa pergunta. No campo geopolítico, por exemplo, não podemos afirmar que as relações internacionais da atualidade obedecem à dinâmica das potências imperialistas de cem anos atrás, quando os Estados beligerantes encerraram a Primeira Guerra mundial, em 1918. A atualidade do campo científico permite-nos afirmar que os avanços das Ciências alcançaram níveis de desenvolvimento inimagináveis numa escala de cem anos. Os mesmos critérios podem ser utilizados para outros campos das relações humanas, todavia para chegar a essas conclusões temos de partir de um ponto, de um marcador temporal, ou seja, de um referencial que ajuda a comparar passado e presente, e esse referencial é o momento que está sendo vivido agora, enraizado no passado recente.

No esforço para compreender o "atual" ou o "agora" vamos atrelar ao significado do termo "atualidades" elementos de outros campos do saber, como a História e a Filosofia, que preferem lançar suas reflexões sobre conceitos como: "Tempo Presente", "Modernidade" e "Contemporaneidade". Esses conceitos serão o ponto de partida para entender a formação de um campo de saber transdisciplinar que cada vez mais busca se debruçar sobre os meandros daquilo que acontece na fronteira dos fatos imediatos.

No campo do conhecimento histórico, por exemplo, alguns historiadores assumiram a análise do tempo numa perspectiva de entender como a narrativa histórica está atrelada às necessidades do presente. O historiador alemão Reinhart Koselleck (19231926) avalia que as sociedades contemporâneas (mas não apenas elas) são profundamente marcadas pela tensão entre as "expectativas de futuro" e o "campo de experiência" (passado). O que um grupo humano deseja do futuro certamente afeta o modo como sente e atua no presente. Afeta também a percepção do passado. Se um grupo luta e defende os direitos humanos (expectativa), olhará de modo muito negativo as ditaduras militares na América Latina ou a experiência do nazifascismo europeu. Se um outro grupo olhar de modo crítico os direitos humanos, certamente terá outra percepção das ditaduras ou dos fascismos. É o engajamento no presente que condiciona o olhar para o passado. É preciso lembrar que mesmo historiadores profissionais não "revivem" o passado, apenas constroem narrativas (no presente). Ainda que bem documentada e cientificamente conduzida a História é marcada pelo presente, vale dizer, pelo atual. Assim sendo, falar de presente e passado não exclui a noção de futuro (KOSELLECK, 2006). Um professor que enfrenta os temas do presente precisa compreender a força do passado e da expectativa de futuro para poder dar conta da complexidade do presente. 
Numa análise mais pessimista sobre o presente, o filósofo polonês Zygmunt Bauman lançou em boa parte de suas obras um olhar sobre vivências de uma temporalidade permeada pela liquidez e pelas relações transitórias. O conceito de modernidade líquida busca dar conta da fluidez e da volatilidade das relações humanas no mundo contemporâneo, diferenciando-se daquelas que se estabeleceram durante a modernidade sólida, a saber, um conjunto de valores e perspectivas iniciadas pelo Renascimento e pelo lluminismo. Foi a partir desses movimentos que as ideias racionalistas ganharam força diante do pensamento tradicional. Para entender a modernidade sólida, um dos exemplos mencionados por Bauman é o da religiosidade, que deixou de ser a única provedora dos preceitos morais, dando lugar à formalização racional das leis e da ética. Outra mudança citada pelo autor é a lógica de funcionamento do trabalho, que anteriormente se baseava em um processo de aprendizagem por imitação e tradição - relação mestres de ofício/aprendizes - e passou a se realizar mediante formas especializadas e formal em escolas técnicas.

Na modernidade líquida toda estrutura social estabelecida ao redor de uma relativa fixidez moderna se esvaiu em benefício das relações voláteis, de múltiplas identidades, permeadas pela permanente noção do que não é fixo, conforme o filósofo descreve a seguir:

São esses padrões, códigos e regras a que podíamos nos conformar, que podíamos selecionar como pontos estáveis de orientação e pelos quais podíamos nos deixar depois guiar, que estão cada vez mais em falta. Isso não quer dizer que nossos contemporâneos sejam guiados tão somente por usa própria imaginação e resolução e sejam livres para construir seu modo de vida a partir do zero e segundo sua vontade, ou que não sejam mais dependentes da sociedade para obter as plantas e os materiais de construção. Mas quer dizer que estamos passando de uma era de "grupos de referência" predeterminados a uma outra de "comparação universal", em que o destino dos trabalhos de autoconstrução individual está endêmica e incuravelmente subdeterminado, não está dado de antemão, e tende a sofrer numerosas e profundas mudanças antes que esses trabalhos alcancem seu único fim genuíno: o fim da vida do indivíduo (BAUMAN, 2001, p. 14-15).

A noção de liquidez, a qual se refere Bauman, diz respeito a essa inconstância e incerteza geradas pela ausência de pontos de referência e modelos socialmente estabelecidos e generalizadores. Gostemos ou não dos padrões estabelecidos no presente (ao mesmo tempo libertadores e opressivos), eles estão visceralmente incrustados no cotidiano, no dia a dia e no ambiente escolar.

O filósofo italiano Giorgio Agamben, por sua vez, não se debruça sobre os temas imediatos que atravessam o tempo presente. Ele está preocupado em responder à seguinte questão: $O$ que é ser contemporâneo? O contemporâneo, para Agamben, é uma condição subjetiva, é um estado de espírito diante das dúvidas do presente. É o indivíduo que mantém fixo o olhar no seu tempo, percebendo assim o escuro e não as luzes (AGAMBEN, 2009, p. 63). O que seria o "escuro", porém, de acordo com o filósofo? É, em grande medida, a indefinição do presente, a sua singularidade perante outras temporalidades. Ser contemporâneo é mergulhar na complexidade e diversidade de narrativas obscuras, confusas e caóticas sobre o presente. O que não é necessariamente ruim. Ser contemporâneo é não fugir do seu tempo, é assumir uma posição de enfrentamen- 
to do desconhecido. Adotar essa postura significa ser capaz de enxergar as rupturas; identificar as consequências de fatos que fraturam processos históricos em andamento; analisar e posicionar-se diante do inesperado que marca a singularidade do tempo presente e daquilo que é visto como atual.

Essa atitude acaba por rejeitar explicações simplistas de que a História sempre se repete, ou de que tudo está previamente definido. Esse pensamento nega a ação humana e o imponderável. É preciso compreender que o presente está em disputa, e que a contemporaneidade representa "uma singular relação com o próprio tempo, que adere a este e, ao mesmo tempo, dele toma distâncias" (AGAMBEN, 2009, p. 64).

Em outras palavras, há muitos modos de ser contemporâneo. Consumir produtos de alta tecnologia não é, automaticamente, ser contemporâneo. Além das questões de classe, que permanecem centrais, ser negro ou branco; homem ou mulher; ser homoafetivo ou heterossexual, jovem ou velho envolvem diferentes formas de experimentar o presente.

Com base nessas contribuições da História e da Filosofia, de que maneira o ensino pode ajudar na construção de uma postura contemporânea sobre o tempo presente? Ou como o presente pode ser compreendido, quando se adota uma postura contemporânea diante dele?

Desde o processo de redemocratização, os princípios educacionais - formulados pelo Estado e pelas instituições educacionais que se reestruturavam - estão assentados numa perspectiva de que o ensino nas diferentes áreas do saber assumiria a missão de ampliar para um número cada vez maior de pessoas o acesso à educação. Esse princípio fundamentou a Constituição de 1988 e a Lei de Diretrizes e Bases para a Educação, aprovada em 1996. A legislação específica proporcionou a criação dos Parâmetros Curriculares Nacionais. Esse conjunto de diretrizes abriu caminhos para reformas curriculares em todo o país, não obstante uma série de críticas que se seguiram logo após o seu lançamento.

Junto aos PCNs, o MEC apresentou uma proposta de temas transversais ${ }^{4}$ - para os Ensinos Fundamental e Médio - cujo objetivo era estimular a formulação de projetos, sequências didáticas e outras iniciativas que proporcionassem debates no espaço escolar. Agregados aos conteúdos disciplinares, ou não, temas como trabalho, consumo, ética, cidadania, saúde, sexualidade e meio ambiente passariam a fazer parte do cotidiano das escolas públicas e privadas, apesar das dificuldades e desafios pertinentes a cada contexto socioeconômico, cultural e religioso ao tratar destes temas em sala de aula.

Os objetivos dos temas transversais estavam pautados na ideia de que a escola também deveria se engajar na construção de um projeto de futuro para o aluno. Os desafios de ampliar e democratizar o ensino, todavia, têm lançado enfrentamentos mais audaciosos para as escolas - públicas e privadas - em todo o país, desde então. Colocar

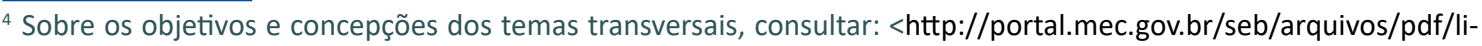
vro081.pdf>. Acesso em: 20 mar. 2018.
} 
em prática um projeto de vida, atrelado à escola, convida alunos e professores a refletirem sobre o mundo em que vivem e o mundo no qual querem viver (CANDELORI, 2011, p. 100).

Numa perspectiva mais otimista do presente, o pedagogo espanhol Xesús R. Jares defendeu durante todo o seu percurso como educador que um dos motes para a realização de um projeto de futuro construído no espaço educacional perpassava pelo conhecimento, defesa e valorização dos direitos humanos e de uma cultura de paz e justiça.

\section{ATUALIDADES, INTERDISCIPLINARIDADE E A BUSCA POR UM MARCO TEMPORAL}

Seja na escola ou em outros espaços de produção e difusão do conhecimento, a tarefa de educar passa pelo desafio de problematizar os diferentes interesses e discursos construídos no presente. Cabe ao professor mostrar caminhos para ajudar o aluno a trilhar uma realidade cada vez mais fluida, fragmentada e por que não dizer, líquida, para retomar a expressão e reflexão de Bauman. O professor que aceita esse desafio carrega consigo a responsabilidade de dominar diversos saberes que margeiam o presente e o passado recente.

Numa perspectiva das disciplinas tradicionais ou no recorte específico da disciplina de Atualidades, recorre-se à historicidade dos fatos que nunca aparecem deslocados de um espaço. É preciso considerar sempre a extensão de um acontecimento num panorama extenso da História e a sua conexão com o espaço social e/ou geopolítico.

Os estudos da Geografia escolar, por exemplo, têm cada vez mais buscado partir da geopolítica para entender processos políticos, econômicos, culturais e sociais que marcam a relação entre os países no tempo presente. $O$ objetivo dessa abordagem é organizar uma série de informações capazes de acompanhar as novas dinâmicas internacionais de um mundo em constante mutação. Há pouco tempo, os geógrafos ensinavam a atualidade das dinâmicas internacionais, partindo de uma explicação sobre os estados nacionais inseridos na lógica da bipolaridade da Guerra Fria. A fragmentação da URSS (1991), a consolidação e os conflitos decorrentes dos processos globalizantes eram (e ainda são) utilizados como marcadores temporais para pensar o tempo presente e a atual dinâmica da geopolítica internacional.

Muitos professores de Atualidades (além dos professores de Sociologia, de Filosofia e de História Contemporânea) têm trabalhado com o conceito "era dos extremos", do historiador britânico Eric Hobsbawm, a fim de demarcar o início da História do tempo presente. Ao delimitar o princípio da década de 90 e o fim do "socialismo real" como o marco que finalizou essa "era", Hobsbawm deixa a porta aberta para pensar o futuro. Afirma o autor:

Não sabemos o que moldará o futuro, embora eu não tenha resistido à tentação de refletir sobre parte desses problemas, na medida em que eles surgem dos escombros do período que acaba de chegar ao fim. Esperemos que seja um mundo melhor, mais justo e mais viável. O velho século não acabou bem (HOBSBAWM, 1995, p. 25-26). 
De acordo com suas palavras, o historiador não assume a perspectiva catastrofista e tampouco propaga o fim da História. Ele afirma que a História continua assumindo uma posição política de refletir sobre "os escombros do período (final do século 20)", além de demonstrar esperanças diante de um "mundo mais justo".

Nessa perspectiva, o professor pode retomar e analisar os "escombros do período" (atravessados por fatos do século 20), convocando os alunos a refletirem sobre as escolhas que a humanidade tem feito, desde o fim da "era dos extremos" até agora, por exemplo.

O conceito de "choque de civilizações" também tem sido usado para entender os conflitos do presente. Nos anos 90, o cientista político norte-americano Samuel P. Huntington defendia que a dinâmica geopolítica a partir daquela década só poderia ser entendida pela lógica do "choque entre civilizações". A expressão tornou-se a síntese da defesa de que o multiculturalismo expôs conflitos e deixou evidentes os "choques" identitários e religiosos por todo o mundo. Outros intelectuais negaram essa teoria. $\mathrm{O}$ filósofo e linguista búlgaro Tzvetan Todorov, em seu livro $O$ medo dos bárbaros, alertou que "o medo dos bárbaros é o que ameaça converter-nos em bárbaros. [...] A história nos ensina: o remédio pode ser pior que a enfermidade" (TODOROV, 2010, p. 15).

Em 11 de setembro de 2001, após o atentado às torres gêmeas, o triunfo da globalização foi colocado em xeque. Para além do âmbito da geopolítica, esse evento exacerbou a espetacularização da violência. Milhões de pessoas assistiram aos aviões lançados em direção ao coração financeiro dos Estados Unidos. Em questão de minutos o mundo começou a ter contato com outros paradigmas - não menos aterrorizantes - que questionavam a supremacia norte-americana.

O sociólogo português Boaventura de Sousa Santos, ao comentar sobre o fundamentalismo islâmico que motivou os ataques, afirmou na ocasião que a ação desses grupos era contrária a um determinado tipo de globalização decorrente de um processo hegemônico neoliberal e imperialista em curso no Oriente Médio, desde meados do século 20 (SANTOS, 2001). Crítico literário e ativista, o palestino Edward Said condenou o ataque aos Estados Unidos, mas evidenciou as consequências imediatas desse atentado: a xenofobia e a islamofobia. Na ocasião, o intelectual rejeitou a tese do "choque de civilizações" para enfatizar o desconhecimento do ocidente em relação aos outros. ${ }^{5}$

Desde então, o marco temporal para a explicação da geopolítica mundial tem sido o 11 de setembro de 2001. As Ciências Sociais, especialmente a Sociologia, têm debatido as transformações sociais, econômicas, políticas e culturais decorrentes dos "choques" multiculturais e da persistência de estruturas desiguais, resultantes das fases do capitalismo internacional e financeiro, predominantes desde as últimas décadas do século passado.

Eis aqui, precisamente, a dificuldade e a complexidade do entendimento de um marco fundador, como o 11 de setembro, que requer uma abordagem em si mesma interdisciplinar, pois demanda de múltiplas áreas do conhecimento.

${ }^{5}$ SAID, Edward. El choque de ignorâncias. Disponível em: <https://elpais.com/diario/2001/10/16/opinion/1003183207 _850215.html>. Acesso em: 26 mar. 2018. 


\section{O ENSINO DE ATUALIDADES E O CRUZAMENTO DE SABERES DISCIPLINARES}

A depender do contexto escolar, é por meio do trabalho realizado nas disciplinas de Geografia, Sociologia, História Contemporânea e nos diferentes componentes da área de Linguagens, que muitos alunos têm contato com temas de atualidades. Convém lembrar, no entanto, que a divisão disciplinar está organizada em torno de disciplinas que determinam seu campo de atuação e disputam com as demais a sua importância social e científica. Para o sociólogo francês Edgar Morin, esse tipo de organização disciplinar instituída no século 19 conduziu ao longo do século 20 à instituição da hiperespecialização do conhecimento. $\mathrm{O}$ ambiente escolar reproduziu essa cultura, marcada pela crescente separação e fragmentação dos saberes.

A interdisciplinaridade, por sua vez, é compreendida no campo da colaboração e da comunicação entre as disciplinas, no entanto ela mantém as especificidades e as particularidades de cada área. Nesse sentido, a interdisciplinaridade opera no contexto da fragmentação do conhecimento, mantendo as delimitações de cada ciência.

De maneira interdisciplinar, a preocupação das práticas docentes de ampliar o repertório do aluno em leitura e produção de texto tem permitido uma abordagem interdisciplinar sobre os temas do presente. Esses temas são traduzidos em sua especificidade textual, seu suporte de produção e divulgação, a partir do entendimento de que a leitura é uma habilidade fundamental para a formação de leitores capazes de apreender a realidade e atuar diante dos desafios da sociedade. ${ }^{6}$

Em sala de aula as temáticas de atualidades são analisadas em textos produzidos em língua vernácula ou estrangeira, considerando o conteúdo e a forma das mais variadas fontes: documentos visuais, fotografias, imagens em documentos, textos literários e jornalísticos, relatos de oralidade (especialmente as entrevistas), charges, histórias em quadrinhos, músicas, conteúdos de portal de notícias, artefatos publicitários, entre outras.

Em muitos contextos escolares, professores de Língua e Produção, Literatura e Língua Estrangeira têm incentivado a leitura dessas e de outras fontes com o objetivo de formar cidadãos academicamente capazes de refletir sobre a realidade em que vivem e atuar nos contextos mais complexos.

Com base na análise dessa perspectiva interdisciplinar do ensino, retomamos o entendimento da educadora brasileira Ivani Fazenda para relembrar que essa proposta pedagógica demanda imersão no trabalho cotidiano, humildade, espera, respeito, desapego e erudição (FAZENDA, 2011, p. 13).

Por volta de 2004 muitas escolas que buscavam o alto rendimento de seus alunos passaram a direcionar, desde então, parte de seus currículos para uma abordagem em que os temas do presente passaram a ser o "fio condutor" de projetos interdisciplinares. Esse processo iniciou-se desde que os resultados do Exame Nacional do Ensino Médio (Enem) começaram a ser utilizados como forma de ingresso nas universidades

\footnotetext{
${ }^{6}$ Consultar os objetivos, as habilidades e competências dos Parâmetros Curriculares para o Ensino Médio, em Língua Portuguesa. Disponível em: <http://portal.mec.gov.br/seb/arquivos/pdf/14_24.pdf>. Acesso em: 20 mar. 2018. 
públicas federais e, portanto, os números obtidos pelas escolas participantes passaram a ser veiculados pela imprensa. A pressão por resultados levou a significativas e controversas mudanças curriculares: aumento demasiado da carga horária e a criação de cursos extracurriculares para abordar temáticas específicas do Enem.

Muitas escolas têm adotado uma disciplina específica para tratar dos temas latentes no tema presente, ressaltando o foco em política nacional e internacional; o entendimento das causas e dos efeitos das crises econômicas; os temas emergenciais que tangenciam as relações sociais, culturais e de gênero; a contemporaneidade do pensamento social, entre outros assuntos e recortes que dialogam diretamente com 0 presente. É provável, porém, que muitos professores sintam-se inseguros em lidar com temas de atualidades.

O funcionamento transdisciplinar do componente curricular Atualidades é intrínseco a sua natureza. Ou seja, os conteúdos programáticos (os fatos analisados nunca são os mesmos) colocam-se em diálogo com a História, Geografia, Filosofia, Sociologia, Artes, Linguagens, além de estabelecer possíveis aproximações com a Biologia, que pode ser evocada ao tratar do racismo, ainda fortemente enraizado em vários cantos do mundo. As especificidades de Atualidades proporcionam também um avanço em relação aos conteúdos procedimentais e, sobretudo, atitudinais, na medida em que auxiliam o aluno na construção de um posicionamento mais contemporâneo diante da realidade do agora.

Para dar conta desses objetivos retomamos Edgar Morin quando argumenta sobre a necessidade de "situar a condição humana no mundo", quando "os conhecimentos derivados das ciências humanas" servirão para evidenciar "a multidimensionalidade e a complexidade humanas" (MORIN, 2010, p. 48). É a prática transdisciplinar que dinamiza e articula os vários saberes, superando a fragmentação do saber isolado e delimitado. Isso posto, a dinâmica transdisciplinar eleva a compreensão do mundo presente, para o qual um dos imperativos é "a unidade do conhecimento", para retomar a expressão do físico romeno Basarab Nicolescu.

A atitude transdisciplinar assumida pela disciplina Atualidades e pelo trabalho conjunto realizado com os outros componentes, resulta em um exercício corajoso de buscar respostas em diferentes lugares e de múltiplos olhares, de modo a permitir que a realidade seja reconhecida em sua totalidade dinâmica e inesgotável.

Algumas experiências de ensino analisadas para a escrita deste artigo, todavia, revelam uma lista de dificuldades com as quais os professores precisam lidar para enfrentar o ensino do tempo presente. Acompanhar com rapidez e eficiência o mundo em que vivemos não é fácil. Alguns temas precisam ser estudados, literalmente, da "noite para o dia". Enfrentar temas altamente polêmicos resulta, muitas vezes, em censura e autocensura, além de questionamentos de toda ordem. Muitas escolas não dispõem ainda de recursos tecnológicos para facilitar o acesso a ferramentas básicas, como Internet rápida. Ainda são poucos os professores que conseguem planejar e disponibilizar materiais com tamanha rapidez, atendendo às urgências de um acontecimento que exige análise imediata. Conseguir superar esses desafios faz toda a diferença, conforme destacou o professor Roberto Candelori, que ministra a disciplina Ética e Cidadania num colégio localizado na zona sul da capital paulista: 
Uma das preocupações curriculares... foi a criação de uma disciplina que pudesse contemplar temas da contemporaneidade. No decorrer de uma década, a dinâmica das aulas foi adaptada às inovações tecnológicas. Em textos "datilografados" ou impressos de imediato em alta resolução, temos acompanhado as facilidades proporcionadas pela democratização e acesso à informação. Isso faz a diferença em nosso trabalho. Estamos falando de um planejamento de aula que tem como ponto de partida, muitas vezes, um fato ocorrido no dia anterior (CANDELORI, 2011, p. 100).

Hoje, a evolução tecnológica em sala de aula tem resultado no aprimoramento das chamadas metodologias ativas. Dependendo do suporte tecnológico disponível na escola, como o acesso à banda larga veloz e à facilidade a computadores portáteis ou tablets, a sala de aula de Atualidades transforma-se num ambiente em que os alunos podem acessar rapidamente notícias; consultar e checar dados; acessar opiniões diferentes, etc. São procedimentos que ajudam o estudante a assumir uma posição mais ativa diante do conhecimento, e que estão atrelados diretamente aos objetivos dessa disciplina. Esta condição logística ideal foi observada em uma das escolas analisadas para a escrita deste artigo e para a reflexão sobre o tema.

Nessa perspectiva, a tecnologia é central no trabalho do professor e no processo de aprendizagem do aluno. Para além do ambiente presencial, de acordo com Bacich e Moran, são as tecnologias digitais que "facilitam a aprendizagem colaborativa, entre colegas próximos e distantes" (2017, p. 11).

Para além do aparato tecnológico, no entanto, é preciso saber conduzir as aulas de Atualidades. A dinâmica mais recorrente observada nessa disciplina, ministrada pelos diferentes professores observados, ${ }^{7}$ é a aula expositiva. Observa-se, contudo, que o diálogo, o debate e as chamadas metodologias ativas ganham cada vez mais espaço, e outras dinâmicas de condução das aulas têm sido frequentemente mais usadas. As escolas observadas dispõem de recursos tecnológicos que possibilitam ao professor ter acesso rápido às notícias do dia, a sites e a outras plataformas virtuais que "hospedam" informações preciosas que serão objetos de análise.

Qualquer tema requer a apresentação e a contextualização da problemática que será discutida. Quando se trata de um conflito entre países, por exemplo, é fundamental exibir suas causas; as estruturas e atuações de personagens, examinando os meios aos quais as partes envolvidas tentam recorrer para chegar a um acordo. As aulas devem ser espaços para realizar esses procedimentos, organizar as informações e alertar os alunos para a necessidade de acompanhar os desdobramentos do conflito, uma vez que nem sempre o professor terá tempo para retomá-lo em suas aulas.

Os desafios para democratizar esses saberes nos espaços educacionais ainda são muitos. Tanto numa abordagem interdisciplinar quanto transdisciplinar desses temas, para a maioria dos alunos, sobretudo da rede pública de ensino, os temas mais complexos que atravessam o presente são acessíveis apenas a leitores assíduos de jornais e sites especializados em notícias. Abordar o funcionamento dos três poderes ou do

7 Os autores deste artigo também ministram ou já ministraram essa disciplina e se incluem neste perfil também. 
sistema eleitoral proporcional no Brasil, ou até discorrer sobre contextos sociais e econômicos de países, como Israel ou Venezuela, significa adentrar em realidades desconhecidas, embora importantes para compreender o mundo em que vivemos.

Se esses temas, para muitos estudantes parecem áridos, outros, no entanto, causam verdadeiro fascínio nas salas de aula de Educação Básica. A guerra é um deles. Guerras étnicas, guerras econômicas, mundiais, "quente, morna ou fria". ${ }^{8}$ A guerra aparece na imprensa, na televisão, no cinema, nas capas de jornais, no vocabulário diário...

Desde 2011 o mundo convive com as notícias sobre a guerra na Síria, país localizado no Oriente Médio, uma das regiões mais conflituosas do mundo. No tempo presente, sociedades do mundo inteiro se horrorizam com as imagens dessa guerra e com o drama dos refugiados sírios. Organizações de ajuda internacional e instituições como a ONU se curvam diante dos limites de atuação no cenário de catástrofe. E de que maneira essa e outras guerras chegam em sala de aula? Como lidar com o tema da violência da guerra, junto a uma faixa etária que adota uma posição contraditória diante dos conflitos? Os jovens sensibilizam-se, condenam a matança, compreendem as causas, mas sentem-se atraídos pelo poderio bélico, pelos tanques, pelas estratégias, pelas ofensivas. Como o professor e a escola devem atuar diante dessas posturas?

A explicação sobre as múltiplas facetas dessa ou de qualquer outra guerra é de fundamental importância. Evitar classificações, cair na bipolaridade, nas divisões do bem e do mal para explicar contextos beligerantes é um dos maiores desafios do professor que se debruça sobre conflitos armados.

Lidar com a guerra, paradoxalmente, na contemporaneidade, é assumir uma atitude de educação para a paz. Para dar conta desse objeto retomamos mais uma vez Xesús R. Jares. O autor defende que o ensino deve estar voltado para a defesa dos direitos humanos; para o estudo das políticas de desarmamento; para a defesa de princípios multiculturais; para o entendimento do conflito e para a compreensão da desobediência civil como forma de resistência (JARES, 2007, p. 48).

No início da década de 80 foi realizado em Paris o 1ำ Congresso Mundial de Educação para o Desarmamento. As resoluções do Congresso, na ocasião, enfatizavam o compromisso dos países ali presentes em desenvolverem estratégias para uma cultura de paz, que perpassaram pelo debate sobre o militarismo e o sistema de guerras; o conceito de segurança internacional e a as causas do subdesenvolvimento econômico. Ao final, o Congresso realizado pela Unesco reafirmou o compromisso com a defesa dos direitos humanos e crítica diante dos discursos de "incitação de guerras e o militarismo em geral". Assim sendo, Xesús Jares propõe alguns norteadores para o trabalho dos professores:

Compreender a história da luta pelos direitos humanos e as liberdades fundamentais; conhecer os artigos da Declaração Universal dos Direitos Humanos e outras declarações vinculadas a ela; identificar casos de violações dos direitos humanos, indagar suas possíveis causas e alternativas de resolução; incentivar o repúdio às

\footnotetext{
${ }^{8}$ Essa frase está contida na letra da música "A canção do senhor da guerra", composta em 1992 por Renato Russo e gravada pela banda Legião Urbana.
} 
violações; conhecer o trabalho de entidades e indivíduos que lutam em defesa dos direitos humanos; Relacionar os direitos humanos às noções de justiça, igualdade, liberdade, paz, dignidade e democracia (JARES, 2007, p. 49).

É importante, nesse sentido, problematizar o militarismo e convocar os alunos e a comunidade escolar para a criação de uma cultura de paz, que compõe o conjunto de objetivos atitudinais dos projetos pedagógicos construídos sob a fundamentação dos direitos humanos e da preservação das instituições democráticas.

\section{PRESENTE: tempo de controvérsias e polarizações}

De que maneira é possível abordar as controvérsias do presente no ambiente escolar? Quantas vezes já não ouvimos o dito popular: "Não se discute política, religião e futebol". Ao contrário do que sugere o ditado, tudo que é relevante deve estar em debate na sociedade e, portanto, nas instituições de ensino, cuja missão é, justamente, refletir e debater o mundo. Como, porém, a escola poderia proceder ao enfrentamento na prática desses temas?

$\mathrm{Na}$ edição digital do dia 20 de abril de 2016, o jornal o Estado de S. Paulo publicou: "O ensino de atualidades: nem alienação, nem proselitismo". Na primeira frase do artigo o autor afirma:

Nestes dias de radicalização política, manter a educação num plano o mais isento possível das polarizações extremistas é uma obrigação ética do educador. Aliás, que me perdoem os "engajados", para um professor, a busca constante de posições isentas é um dever que sobrenada a qualquer conteúdo. ${ }^{9}$

Como o professor deveria evitar "contaminar-se" pelas paixões que esses temas suscitam? Percebemos que o texto tem uma tomada de posição clara a respeito do papel do educador e do ensino de Atualidades diante das polarizações do tempo presente. Por trás desse discurso esconde-se o mito da neutralidade cientifica, mas também "a ideologia da neutralidade ideológica nas ciências sociais", conforme problematizou o educador espanhol Sánchez Vázquez.

Para educadores, sociólogos, economistas, filósofos, cientistas políticos e historiadores (estes últimos mais recentemente), estudar o tempo presente é analisar e entender os meandros dos processos políticos, sociais, culturais e econômicos, que estão próximos temporalmente do sujeito que faz a análise.

Analisar o tempo presente é encarar um emaranhado de representações que interpretam os acontecimentos ainda inacabados, uma vez que os estudiosos do tempo presente não dispõem de narrativas acerca de um panorama histórico de longa duração, no qual os acontecimentos já se encerraram. É necessário buscar desvendar as intencionalidades dos sujeitos que constroem os discursos, identificar os seus lugares de

\footnotetext{
${ }^{9}$ Disponível em: <http://educacao.estadao.com.br/blogs/colegio-faap/o-ensino-de-atualidades-nem-alienacao-nemproselitismo/>. Acesso em: 19 mar. 2018.
} 
produção, ${ }^{10}$ especialmente quando o posicionamento político desses emissores é aparentemente neutro e objetivo. Qualquer um que analise o presente é testemunha dessa temporalidade. Se isso vale para a narrativa das Ciências Sociais e Humanas, também é válido para o conhecimento produzido na escola.

No caso da história do imediato, o historiador e jornalista francês Jean Lacouture reafirma a proximidade entre o sujeito e a narrativa do presente, evidenciando a rapidez na execução feita pelo protagonista ou por "uma testemunha vizinha do acontecimento, da [narrativa em torno da] decisão analisada" (LACOUTURE, 1990, p. 216).

Quando discorre sobre a relação entre memória e esquecimento o filósofo francês Paul Ricoeur lança o seu olhar para a seletividade da narrativa sobre o passado e sobre o presente. Essa relação sempre requer uma seleção. A "representação historiadora", 11 para usar a expressão do autor, representa um processo complexo ligado à linguagem e à narrativa. Uma história pode ser contada de várias maneiras, o que não quer dizer que o compromisso com as fontes e com a verdade não permaneçam como meta. Exatamente por isso não existe uma apreensão "neutra" do passado, tampouco do presente. Ainda que submetido aos rigores da disciplina, a história está em disputa, porque o presente e o futuro também estão.

Muitas vezes cabe a outras formas de conhecimento - a arte, por exemplo - desmontar a veracidade e a pretensa clareza de alguns discursos propagados por jornalistas, cientistas sociais ou mesmo analistas do tempo presente. Quando esses discursos tornam-se "lugares-comuns", sobra pouca margem para a problematização. Estar atento ao tempo presente é ainda identificar de que maneira outras formas de conhecimento interrogam as limitações dos discursos pretensiosamente neutros ou verdadeiros.

A variedade das interpretações aplica-se não só às Ciências Humanas e de maneira não tão óbvia ao discurso jornalístico, parte dele ainda arraigado na ideia de neutralidade presente na escrita, sobretudo no texto noticioso. Nunca é exagero relembrar o mito da neutralidade científica e o mito da imparcialidade. Nesse sentido, alerta-nos o historiador inglês Peter Burke: "Nossas mentes não refletem diretamente a realidade. Só percebemos o mundo através de uma estrutura de convenções, esquemas e estereótipos, um entrelaçamento que varia de uma cultura para outra" (1992, p. 15).

Burke retoma em seu texto os paradigmas da objetividade, da cientificidade e mesmo da validade do conhecimento histórico. Essa enumeração de questões ainda tem representado inúmeras inquietações para historiadores, professores e pesquisadores das Ciências Humanas e outros profissionais interessados em construir uma apreensão "legítima" das relações humanas, da História e do presente.

\footnotetext{
$\overline{10}$ Para o historiador francês Michel de Certeau todo e qualquer texto (inclusive a historiografia) deve ser compreendido a partir do lugar institucional e social no qual ele está inserido. Desse modo, é preciso compreender os interesses e compromissos, inclusive políticos ou econômicos, de classe, etnia ou gênero que acabam por definir o que pode ser escrito e o que deve ser vetado. $O$ peso das instituições exerce considerável influência na formação do olhar contido no texto, bem como na legitimação e na credibilidade que o mesmo adquire. Cf.: CERTEAU, Michel de. A Operação Historiográfica. In: A escrita da História. Rio de Janeiro: Forense Universitária, 1982. p. 56-107.

${ }^{11}$ O tema da "representação historiadora", da narrativa, da interpretação e da memória é uma constante na obra de Paul Ricoeur, no entanto essas questões aparecem de modo decisivo na obra: RICOEUR, Paul. Tempo e narrativa. Campinas: Papirus, 1997. Vols. 1, 2 e 3.
} 
Em menor ou maior escala, analistas e professores, cujo tempo presente é objeto de atuação, se veem num paradoxo: mostrar comprometimento com a contemporaneidade sem assumir deliberadamente um lado do contexto analisado. Esse distanciamento, no entanto, é possível?

No Brasil a polarização do cenário político desde meados dos anos 2000 vem impondo um debate difícil, no qual, muitas vezes, a tomada de posição faz-se necessária. Como não condenar o assassinato como linguagem política, tal como ocorreu com a vereadora Marielle Franco, morta a tiros no Rio de Janeiro, em 14 de março de 2018?

Nenhuma análise, seja sobre o passado ou sobre o presente, é neutra. Toda linha que se escreve está sujeita a interesses e usos funcionais específicos. Nenhum analista do presente pode fugir da sua própria inserção histórica.

\section{ESTRATÉGIAS DE COMO ENSINAR O PRESENTE NO TEMPO PRESENTE}

Hoje, um dos desafios do educador é aceitar que a "luz" da verdade absoluta não pode ser revelada, simplesmente porque ela não existe. É necessário convencer a si e aos outros de que o conhecimento sobre o presente é sempre provisório, parcial e cheio de reparos. Ao mesmo tempo que essas afirmações são feitas, o sujeito do tempo presente depara-se com um excesso de informações inédito na História da humanidade. A maioria dessas informações são instantâneas e provêm do mundo virtual. Basta um simples acesso no celular, conectado à Internet, e o indivíduo já é transportado rapidamente para uma enxurrada de textos, imagens e gêneros carregados de dados que precisam ser rapidamente codificados.

No caso específico das crianças e adolescentes, quando não estão conectadas e interagindo no universo de notícias e opiniões virtuais, eles ouvem de orelhada e enxergam pelo olhar de outros um emaranhado de informações cada vez mais fragmentadas, recortadas e descontextualizadas.

De acordo com Luiz Alberto Grijó, é na Internet o lugar no qual as pessoas recoIhem "informações", "impressões" e "legitimidade", além de ancorar suas "opiniões". O espaço virtual passa a ocupar mais ou menos o lugar que a "voz das ruas" ocupou outrora, "quando as redações dos jornais se localizavam nos centros das cidades e o jornalista recolhia as vozes a partir do contato interpessoal" (GRIJÓ, 2014, p. 284). E é por causa da Internet que ocorre o aumento de "formadores" de opiniões com alcance mensurado pelo número de "seguidores" no Twitter e nos perfis de redes sociais como o Facebook.

As aulas de Atualidades são espaços nos quais os jovens são convidados a adotar posturas ativas diante de um contexto em que eles se sentem cada vez mais obrigados a apresentar um posicionamento pessoal. As demandas dos vestibulares, os textos dissertativos com soluções de intervenção social e política e a resolução de problemas dos quais pouco conhecem são desafios diários, sobretudo para os jovens que cursam as séries do Ensino Médio.

Como, no entanto, opinar e se posicionar diante de fatos inacabados e de análises fragmentadas sobre o presente? O que as escolas têm feito para lidar com o excesso de informações e com o desconhecimento de como lidar com elas? Como o ensino pode 
contribuir para ajudar os educandos a diferenciar a informação fugaz e a opinião superficial daquilo que é conhecimento resultante de uma metodologia de sistematização, análise e confrontamento de fontes?

Essas perguntas podem despertar dúvidas acerca do caráter não científico e duvidoso de textos e imagens que pretendem decifrar o "aqui e agora" em decorrência da proximidade temporal do analista com o fato analisado, no entanto é preciso insistir que nunca vai existir um conhecimento totalizado e finalizado, nem sobre o passado, tampouco sobre o presente.

O método - termo herdado do grego antigo que significa "caminho" - é uma fusão de operações técnicas e teóricas que orientam não apenas a abrangência empírica das fontes, mas também a construção de quem elabora a narrativa.

A sala de aula ou outros espaços que refletem sobre "atualidades" devem trilhar o caminho que preza pelos conceitos consagrados pelos pressupostos científicos, pela pluralidade de ideias e pelo respeito aos princípios democráticos. Os discursos reproduzidos em aula precisam ser confrontados com dados numéricos e outras referências que ajudem a romper com o dogmatismo e o pensamento único. Consciente dessa dificuldade, o professor deve conduzir as dúvidas dos alunos para a investigação, fundamentada em métodos analíticos e procedimentos de localização e interpretação de diferentes fontes, além da sistematização das informações obtidas. Apresentar situações-problemas, aventar hipóteses, analisar fontes de naturezas diversas, aplicar conceitos e categorias de múltiplas disciplinas, confrontar teses clássicas, são habilidades que fazem parte da pesquisa escolar.

A matéria-prima utilizada nas aulas de Atualidades é o texto jornalístico: notícias, manchetes, editoriais, opiniões do leitor, colunas, etc. No século 20 eram a imprensa e os textos jornalísticos que agenciavam significados e produziam as narrativas mais enfáticas e "verdadeiras" acerca de um fato. Hoje, quem cumpre essa função? A historiadora Sônia Meneses alerta para o fato de que a imprensa continua assumindo a formulação da "palavra final" sobre os fatos emblemáticos que marcam o nosso cotidiano. A rapidez da divulgação dos fatos exige que "a notícia/informação/conhecimento", formulada em percursos variados, às vezes de forma caótica, dispersa ou disciplinada, seja capaz de produzir "um saber marcado pela urgência das ocorrências cotidianas" (MENESES, 2014, p. 232).

O professor de Atualidades dificilmente poderá trabalhar com seus alunos sem recorrer a essa matéria-prima, substância por excelência transdisciplinar. A democratização da produção de informação e a difusão de novos suportes (não mais o impresso, ou os sites especializados em notícias) tornou a autoria dos textos e das imagens (simbolizados em twits, hashtags, posts, "memes" e fotos-montagens) representações nebulosas. Os especialistas em comunicação têm alertado para o fato de que o ambiente virtual ajudou na fundamentação da chamada pós-verdade. Trata-se de um contexto comunicacional profundamente ambientado nas redes sociais e alimentado por fake news, como têm sido nomeadas as notícias falsas, não raro insultuosas, mas disseminadas como absolutamente verdadeiras. 
Ambientes politicamente polarizados tornam ainda mais candente o assunto. Em 2016, a Oxford Dictionaries, ${ }^{12}$ da Universidade de Oxford, na Inglaterra, elegeu o vocábulo "pós-verdade"13 como a palavra do ano em língua inglesa, atestando a preocupação da instituição com a disseminação de informações deliberadamente falsas, em geral portadoras de interesses políticos ou econômicos.

Um discurso, para adquirir o mínimo de credibilidade, pode estar amparado em informações passíveis de verificação e análises fundamentadas em conceitos aceitos pela comunidade científica ou pelos especialistas em um assunto. Esse lastro certamente agrega credibilidade ao conhecimento produzido.

Como, no entanto, a pós-verdade alcança o estatuto de verdade? Isso tende a acontecer quando milhares ou milhões de pessoas reproduzem um boato ou uma mentira, levando os indivíduos, sem recursos para checar a informação ou mesmo desejosos de acreditar, a "replicarem" a informação como se fosse verdadeira. Quanto maior for o número de pessoas a difundirem a informação falsa, mais verossímil ela se torna. As "bolhas virtuais" são verdadeiros viveiros de fake news, pois as pessoas destituídas do contraditório tendem a aceitar a informação que, de algum modo, Ihes convém.

Nesses casos, cabe ao professor criar junto com os alunos uma cultura salutar de ceticismo e de interrogação, amparada em ferramentas de checagem das informações. Lembre-se que o princípio da ciência é a dúvida. O ambiente escolar deve emular esse princípio, a fim de difundir a responsabilidade no uso das informações. Recorrer a jornais conceituados, dos quais se espera responsabilidade na difusão da informação, é uma das estratégias possíveis. É preciso lembrar, contudo, que as empresas de comunicação não são neutras, nem imparciais, mas signatárias de certas posições (políticas, econômicas e culturais), nem sempre admitidas publicamente, o que afeta o modo como repercutem as informações. Assim, cabe ao professor incentivar os alunos a identificar os diferentes modos como os órgãos de imprensa se posicionam diante da matéria jornalística que produzem.

No Brasil, para enfrentar o presente e para ganhar novos leitores, muitos jornais e revistas criaram fascículos para auxiliar o trabalho dos professores de Atualidades ou os docentes que incorporam à sua prática o estudo de temas do presente. Na década de 90 a revista Veja, e nos anos 2000 a revista Carta Capital criaram suplementos nos quais desenvolveram sequências didáticas pautadas em fatos ocorridos há poucos dias. Os dois semanários, por exemplo, atrelavam as sequências didáticas ao trabalho com reportagens publicadas nas suas revistas.

\footnotetext{
12 Disponível em: <https://en.oxforddictionaries.com/word-of-the-year/word-of-the-year-2016>. Acesso em: 28 mar. 2018.

${ }^{13} \mathrm{O}$ conceito é datado do início do novo século, embora o debate sobre a chamada pós-verdade tenha se avolumado nos últimos anos, especialmente com a eleição de Donald Trump para presidente dos Estados Unidos, quando uma série de notícias falsas foram produzidas pelos apoiadores do candidato do Partido Republicano. Em 2004 Ralph Keyes, um escritor e ensaísta norte-americano, batizou seu livro como The Post-Truth Era: Dishonesty and Deception in Contemporary Life. O livro é, possivelmente, mais atual hoje do que quando o texto foi originalmente publicado. Cf.: KEYES, Ralph. The post-truth era: dishonesty and deception in contemporary life. Nova York: St. Martin's Press, 2004.
} 
Em meados dos anos 2000, a editora Abril criou um fascículo chamado Guia de Atualidades. Até hoje, semestralmente, o Guia apresenta reportagens e artigos exclusivos pautados por uma agenda que atravessa o tempo presente, e cujos desdobramentos podem ser vistos num processo de longa duração. Em uma rápida análise dessas fontes percebemos a intencionalidade de direcionar as orientações didáticas contidas nesses materiais para professores e alunos do Ensino Médio.

O ensino do presente deve ir além do repasse de informações veiculadas e pautadas pelos meios de comunicação. Assim sendo, não só a partir do texto e da imagem jornalística a compreensão sobre o tempo presente é possível. As fotografias, as histórias em quadrinhos, as charges, a literatura, os filmes, as séries e as músicas, dos mais variados gêneros, abordam temas silenciados pelos discursos hegemônicos, além de permitirem mostrar outros regimes discursivos, que ajudam a adotar uma atitude contemporânea diante do mundo e da realidade social, a exemplo do funk e do rap. Resta ao professor diante de diferentes tipos de vestígios da realidade contemporânea encontrar o melhor "modelo", mesmo que provisório.

É preciso evidenciar, todavia, duas características fundamentais na ação de um educador de temas do presente ou de um professor da disciplina Atualidades: o respeito às opiniões distintas e a necessidade de uma profunda e transdisciplinar leitura da realidade social, econômica e cultural sobre a qual ele e seus alunos se debruçam. Essas caraterísticas orientam qualquer ação educativa voltada para a inserção do indivíduo na contemporaneidade. Sem esses pré-requisitos não há inventividade de métodos ativos que se mantenha de pé neste campo do saber.

Pesquisar no espaço escolar é uma dessas dinâmicas ativas. É por meio da investigação que o aluno acessa discursos, checa dados e desenvolve uma atitude mais ativa e responsável sobre a aprendizagem dos conteúdos. Em meio ao entendimento do mundo a pesquisa e o debate também constituem ferramentas para o entendimento de si.

Nesse sentido, sobre o processo de ensino-aprendizagem Paulo Freire é assertivo quando afirma: "Já não se pode afirmar que alguém liberta alguém, ou que alguém se liberta sozinho, mas os homens se libertam em comunhão" (FREIRE, 2004, p. 75). 0 professor não pode adotar o comportamento de que ele tem o domínio completo dos temas, cabendo a ele a missão de conduzir os alunos à libertação das amarras da manipulação dos discursos hegemônicos.

O educador canadense Peter Maclaren, desde meados da década de 90, vem provocando os professores sobre a necessidade de abastecer os estudantes com uma linguagem de análise que ajude os "cyborgs" (é assim que ele chama os jovens do presente), a adquirir "uma compreensão crítica de suas próprias "tecno-identidades" (MCLAREN, 2000, p. 47). Nessa direção, o professor acaba por ajudar os alunos a descobrirem o que lhes interessa dentro e fora da sala de aula. Para isso a leitura, a investigação e o registro são procedimentos para serem ensinados junto com a compreensão da realidade vivida. 
Com base nas questões até agora expostas, este artigo considera que o educador que assume o campo das atualidades como objeto de sua docência deve colocar-se no papel de traduzir não só "o escuro do presente", mas também deve assumir a tarefa de "ser contemporâneo" na construção de um projeto de transformação, conforme sugere Agamben.

Para consolidar essa prática, porém, os professores devem ser capazes de transitar por diferentes saberes, o que demanda tempo e formação contínua, nem sempre disponíveis ao professorado brasileiro. Para os limites deste artigo não cabe recuperar a complexidade dessas questões, mas alertar que os projetos educacionais que debatem os desafios da contemporaneidade não devem esconder-se por trás de uma postura falsamente imparcial, como advogam os militantes do movimento Escola Sem Partido (cuja base epistemológica, o positivismo, foi superada há muito tempo). Ao contrário, cabe ao professor apresentar a complexidade do presente, mapear a diversidade e a dificuldade de nosso tempo e, se for o caso, se posicionar, mas apresentando com honestidade intelectual teses e visões divergentes.

Somente por meio desse compromisso é que o ensino de Atualidades conseguirá se firmar como um campo de saber apto e transdisciplinar para compreender as complexidades do mundo contemporâneo.

\section{REFERÊNCIAS}

AGAMBEN, G. O que é o contemporâneo? E outros ensaios. Chapecó: Ed. da Unochapecó, 2009.

BACICH, Lilian; MORAN, J. M. (Org.). Metodologias ativas para uma educação inovadora: uma abordagem teórico-prática. 1. ed. Porto Alegre: Penso, 2017. V. 1.

BAUMAN, Zygmunt. Modernidade líquida. Rio de Janeiro: Jorge Zahar, 2001.

BURKE, Peter (Org.). A escrita da história. São Paulo: Ed. Unesp, 1992.

CANDELORI, Roberto. O desafio de educar no século XXI. Contribuições da disciplina de Ética e Cidadania. Revista da Móbile, São Paulo, ano 9, n. 9, dez. 2011.

CERTEAU, Michel de. "A Operação Historiográfica". In: A escrita da história. Rio de Janeiro: Forense Universitária, 1982.

CHAUVEAU, Agnes; TÈTART, Phillipe (Org.). Questões para a história do presente. Bauru, SP: Edusc, 1999. FAZENDA, Ivani Catarina Arantes. Interdisciplinaridade, vol 1, n. 1, out. 2011. Publicação Oficial do Grupo de Estudos e Pesquisa em Interdisciplinaridade (Gepi). Educação: Currículo. Linha de Pesquisa: Interdisciplinaridade. São Paulo: PUC/SP, São Paulo, 2011.

FREIRE, Paulo. Pedagogia da tolerância. Série Paulo Freire. São Paulo: Ed. Unesp, 2004.

GRIJÓ, Luiz Alberto. A mídia brasileira do século XXI: desafios da pesquisa histórica. In: DELGADO, Lucília de Almeida Neves; FERREIRA, Marieta de Moraes. História do tempo presente. Rio de Janeiro: FGV Editora, 2014.

HOBSBAWM, Eric J. Era dos extremos: o breve século XX: 1914-1991. São Paulo: Companhia das Letras, 1995.

HUNTINGTON, Samuel. O choque das civilizações e a recomposição da nova ordem mundial. Rio de Janeiro: Objetiva, 1997.

JARES, Xesús R. Educar para a paz em tempos difíceis. São Paulo: Palas Athena, 2007.

KEYES, Ralph. The post-truth era: dishonesty and deception in contemporary life. Nova York: St. Martin's Press, 2004.

KOSELLECK, Reinhart. Espaço de experiência e horizonte de expectativas. In: Futuro passado: contribuição à semântica dos tempos históricos. Rio de Janeiro: Contraponto, 2006.

LACOUTURE, Jean. A história imediata. In: LE GOFF, Jacques (Org.). A história nova. São Paulo: Martins Fontes, 1990. 
MCLAREN, Peter. Multiculturalismo revolucionário: pedagogia do dissenso para o novo milênio. Porto Alegre: Artes Médicas Sul, 2000.

MENESES, Sônia. A operação midiográfica: da escritura do evento na cena pública à inscrição do acontecimento no tempo - a mídia, a memória e a história. In: DELGADO, Lucília de Almeida Neves; FERREIRA, Marieta de Moraes. História do tempo presente. Rio de Janeiro: FGV Editora, 2014.

MORIN, Edgar. Ciência com consciência. 13. ed. Rio de Janeiro: Bertrand Brasil, 2010.

NICOLESCU, Basarab. O manifesto da transdisciplinaridade. São Paulo: Trion, 1999.

RICOEUR, Paul. Tempo e narrativa. Campinas: Papirus, 1997. Vols. 1, 2 e 3.

SAID, Edward. El choque de ignorancias. El País. 16 de outubro de 2001. Disponível em: <https://elpais. com/diario/2001/10/16/opinion/1003183207_850215.html>.

SÁNCHEZ VÁSQUEZ, Adolfo. A tiempo y a destiempo. Antología de ensayos. México: Fondo de Cultura Económica, 2003.

SANTOS, Boaventura de Sousa (Org.). Os processos da globalização. In: SANTOS, Boaventura de Sousa (Org.). Globalização: Fatalidade ou utopia? Porto: Afrontamento, 2001.

SANTOS, Márcia Juliana. As charges nas ruas: A primavera árabe nos traços de Carlos Latuff e Ali Ferzet. Projeto História: Revista do Programa de Estudos Pós-Graduados de História, v. 46, mar. 2014.

TODOROV, Tzvetan. $O$ medo dos bárbaros: para além do choque das civilizações. Rio de Janeiro: Vozes, 2010. 